\title{
The contribution of CYP2C gene subfamily involved in epoxygenase pathway of arachidonic acids metabolism to hypertension susceptibility in Russian population
}

Alexey Polonikov, Marina Bykanova, Irina Ponomarenko, Svetlana Sirotina, Anna Bocharova, Kseniya Vagaytseva, Vadim Stepanov, Mikhail Churnosov, Olga Bushueva, Maria Solodilova, Yaroslav Shvetsov \& Vladimir Ivanov

To cite this article: Alexey Polonikov, Marina Bykanova, Irina Ponomarenko, Svetlana Sirotina, Anna Bocharova, Kseniya Vagaytseva, Vadim Stepanov, Mikhail Churnosov, Olga Bushueva, Maria Solodilova, Yaroslav Shvetsov \& Vladimir Ivanov (2017): The contribution of CYP2C gene subfamily involved in epoxygenase pathway of arachidonic acids metabolism to hypertension susceptibility in Russian population, Clinical and Experimental Hypertension, DOI: 10.1080/10641963.2016.1246562

To link to this article: http://dx.doi.org/10.1080/10641963.2016.1246562

Published online: 17 May 2017.

Submit your article to this journal ¿

View related articles $₫$

View Crossmark data $₫$ 


\title{
The contribution of CYP2C gene subfamily involved in epoxygenase pathway of arachidonic acids metabolism to hypertension susceptibility in Russian population
}

\author{
Alexey Polonikova,d, Marina Bykanovaa,e, Irina Ponomarenkoa, Svetlana Sirotinaa, Anna Bocharova ${ }^{\mathrm{b}}$, \\ Kseniya Vagaytseva ${ }^{b}$, Vadim Stepanov ${ }^{b}$, Mikhail Churnosov'c, Olga Bushuevaa,e, Maria Solodilovaa, Yaroslav Shvetsova, \\ and Vladimir Ivanov
}

\begin{abstract}
aDepartment of Biology, Medical Genetics and Ecology, Kursk State Medical University, Kursk, Russian Federation; ${ }^{\text {b} E v o l u t i o n a r y ~ G e n e t i c s ~}$ Laboratory, Research Institute for Medical Genetics, Tomsk, Russian Federation; 'Department of Medical Biological Disciplines, Belgorod State University, Belgorod, Russian Federation; 'Laboratory of Statistical Genetics and Bioinformatics, Research Institute for Genetic and Molecular Epidemiology, Kursk, Russian Federation; 'Laboratory of Genomic Research, Research Institute for Genetic and Molecular Epidemiology, Kursk, Russian Federation
\end{abstract}

\begin{abstract}
Numerous studies demonstrated an importance of cytochrome P-450 epoxygenase pathway of arachidonic acids metabolism for the pathogenesis of essential hypertension (EH). The present study was designed to investigate whether common single-nucleotide polymorphisms (SNP) of CYP2C gene subfamily such as CYP2C8 (rs7909236 and rs1934953), CYP2C9 (rs9332242), and CYP2C19 (rs4244285) are associated with susceptibility to $\mathrm{EH}$ in Russian population. A total of 816 unrelated Russian individuals comprising $425 \mathrm{EH}$ patients and 391 normotensive controls were included into the study. Genotyping of SNPs was performed using the MassARRAY 4 system. SNP rs7909236 of CYP2C8 was significantly associated with increased risk of EH (OR adjusted for sex and age was $2.9995 \% \mathrm{Cl} 1.39-6.44$, $P=0.005)$. SNPs rs 1934953 CYP2C8 and rs4244285 of CYP2C19 showed association with EH risk but at a borderline statistical significance $(P \leq 0.04)$. Combination of genotypes CYP2C8 rs7909236 $\Pi$ and CYP2C19 rs4244285 GG was associated with increased EH risk (OR $3.3495 \% \mathrm{Cl} 1.48-7.51, P=0.004)$. Genotype-phenotype correlation analysis showed that the levels of CYP2C8 mRNA were significantly correlated with SNP rs7909236 $(P=0.01)$. in silico functional prediction analysis revealed the functionality of majority of investigated SNPs. Thus, genes of CYP2C subfamily are important genetic determinants of susceptibility to essential hypertension in Russians.
\end{abstract}

\section{ARTICLE HISTORY}

Received 22 July 2016 Revised 4 September 2016

Accepted 12 September 2016 Published online 11 May 2017

\section{KEYWORDS}

Arachidonic acid metabolism; CYP2C8. essential hypertension epoxyeicosatrienoic acids; genetic susceptibility; single-nucleotide polymorphism

\section{Introduction}

Hypertension is a complex multifactorial disease with high worldwide prevalence and associated increased rates of morbidity, mortality, and disability from cardiovascular and cerebrovascular diseases $(1,2)$. Despite considerable research, the etiology of hypertension in most cases remains elusive, that is, the reason to define the disease as essential hypertension (EH). Although, genome-wide association scans and candidate gene studies have successfully identified a number of common genetic variants influencing blood pressure and hypertension susceptibility (3-7), nevertheless, identification of new potential genes and pathways related to disease pathogenesis remains a matter of great interest.

According to the present available evidence, alterations in the metabolism of arachidonic acid (AA) and other polyunsaturated fatty acids are involved into the pathogenesis of hypertension and other cardiovascular diseases (8-10). Incorporated into membrane phospholipids, AA is hydrolyzed by a $\mathrm{Ca}^{2+}$-activated phospholipase $\mathrm{A}_{2}$ upon endogenous stimuli and oxidized by cytochrome P450 epoxygenases to form epoxyeicosatrienoic acids (EETs), potent lipid mediators with a wide range of biological events in the cardiovascular system $(11,12)$. Functional effects of EETs are realized through activating receptor-mediated signaling pathways and ion channels (12). A number of preclinical and genetic epidemiologic studies demonstrated that CYP-derived epoxyeicosatrienoic acids possess potent vasodilatory, angiogenic, and anti-inflammatory properties in the heart, vasculature, and kidney and that genetically determined alterations in the metabolism of EETs may play an important role in the pathophysiology of many cardiovascular disorders, including hypertension and its complications $(13,14)$.

Cytochrome P450 2J (CYP2J2) and 2C (CYP2C8, CYP2C9 and CYP2C19) are the two major subfamilies of CYP enzymes responsible for the biosynthesis of EETs in the cardiovascular system (15, 16). Interestingly, experimental studies demonstrated that increased expression of endothelial CYP2 epoxygenases lowers blood pressure and attenuates hypertension-induced renal injury in mice (17). Taken into account that genetically determined differences in the expression or activity of these enzymes could explain interindividual risks in developing hypertension, exploitation of single-nucleotide polymorphisms (SNP) in genes encoding these enzymes is become an attractive option for examining genetic etiology of essential hypertension. Pursuing this interest,

CONTACT Alexey Polonikov polonikov@rambler.ru Department of Biology, Medical Genetics and Ecology, Kursk State Medical University, 3 Karl Marx St., Kursk 305041, Russian Federation.

Color versions of one or more of the figures in the article can be found online at www.tandfonline.com/iceh.

(c) 2017 Taylor \& Francis 
several genetic association studies have been undertaken to investigate the relationship between SNPs in CYP epoxygenase genes and hypertension susceptibility in different human populations. However, no association studies of CYP2C and CYP2J gene subfamilies have been so far undertaken on the animal model of human hypertension. The relationship of polymorphisms of CYP2C and CYP2J gene subfamilies and essential hypertension risk has been investigated in various races and ethnicities including African-Americans (18, 19), Chinese (20, 21, 22), Korean (23), and Arab $(24,25)$ populations. A few genetic association studies investigated CYP2C and CYP2J2 gene subfamilies SNPs and hypertension risk have been done in European populations (18, $26,27)$. However, these studies have yielded controversial results and show that the pathogenetic role of CYP2C and CYP2J2 gene subfamilies should be clarified by independent studies in different populations. Our previous study in Russians has found a strong association between promoter polymorphism -76G $>\mathrm{T}$ ( $\mathrm{rs890293)}$ of the CYP2J2 gene and the risk of essential hypertension (26) highlighting the importance of P-450 epoxygenase pathway of arachidonic acid metabolism in the pathogenesis of hypertension in our population. Therefore, the present study was designed to investigate whether common SNPs of CYP2C subfamily genes such as CYP2C8 (rs7909236 and rs1934953), CYP2C9 (rs9332242), and CYP2C19 (rs4244285) are associated with susceptibility to essential hypertension in Russian population.

\section{Methods}

\section{Study Population}

A total of 816 unrelated Russian individuals comprising 425 patients with essential hypertension EH and 391 normotensive controls were selected from the study samples recruited in our previous studies $(26,28,29)$. The study protocol was approved by Ethical Review Committee of Kursk State Medical University, and written informed consent was obtained from each participant before the study. Diagnosis of essential hypertension was established by qualified cardiologists according to WHO criteria. All hypertensive patients had no clinical signs, symptoms, and laboratory findings suggestive of secondary hypertension. As can be seen from Table 1, patients with $\mathrm{EH}$ were matched to healthy controls on sex and age $(P>0.05)$. A percentage of positive family history of hypertension was significantly greater in hypertensive patients versus normotensive controls. No differences were found between the groups regarding to other baseline characteristics.

\section{Genetic analysis}

Genomic DNA was isolated from venous blood samples using a standard phenol/chloroform procedure. Genes encoding

Table 1. Baseline characteristics of the study groups.

\begin{tabular}{lccc}
\hline & Controls, & EH patients, & \\
Baseline characteristics & $n=391$ & $n=425$ & $P$-value \\
\hline Age, mean \pm standard deviation & $58.9 \pm 8.4$ & $59.0 \pm 8.3$ & 0.84 \\
Males, $n(\%)$ & $228(58.3)$ & $261(61.4)$ & 0.37 \\
$\begin{array}{l}\text { Body mass index } \\
\left(\mathrm{kg} / \mathrm{m}^{2}\right), \text { mean } \pm \text { standard deviation }\end{array}$ & $27.5 \pm 7.7$ & $28.2 \pm 9.4$ & 0.24 \\
$\begin{array}{l}\text { Positive family history } \\
\quad \text { of hypertension, } n(\%)\end{array}$ & $183(46.8)$ & $251(59.1)$ & $\mathbf{0 . 0 0 1}$ \\
Bolded is statistically significant $P$ value. & & & \\
\hline
\end{tabular}

CYP2C subfamily epoxygenases of responsible for the metabolism of arachidonic acid into vasoactive eicosanoids were selected based on their involvement in the pathway using KEGG PATHWAY (www.genome.jp/kegg/pathway.html), Reactome Pathway (www.reactome.org), and PharmGKB (www.pharmgkb.org) databases. Four common SNPs of the CYP2C gene subfamily as CYP2C8 (rs7909236, rs1934953), CYP2C9 (rs9332242), and CYP2C19 (rs4244285) were selected for this study. Genotyping of SNPs was performed using the MassARRAY 4 system (Agena Bioscience Inc, San Diego, CA, USA) at the Core Facility "Medical Genomics" in the Research Institute of Medical Genetics (Tomsk, Russia). We failed to genotype eight controls and four cases EH patients because of low quality of their DNA samples.

To evaluate genotype-phenotype correlations, we used the genotype and mRNA expression data available for 270 HapMap subjects from four populations and SNPexp v1.2 online tool (http://app3.titan.uio.no/biotools/tool.php?app= snpexp). The functionality of selected SNPs was also assessed in silico by the SNP function prediction tool developed by $\mathrm{Xu}$ and Taylor (30) and available online at the SNPinfo Web Server (https://snpinfo.niehs.nih.gov/snpinfo/snpfunc.htm).

\section{Data Analysis}

Allele frequencies were estimated by the gene counting method, and the chi-square test was used to identify significant departures from Hardy-Weinberg equilibrium. The distributions of the genotypes and their combinations between patients and controls were evaluated by logistic regression analysis. Categorical variables such gender and family history of hypertension were also compared by using the chi-square test. These statistics were calculated by using STATISTICA software for Windows 10.0 (StatSoft Inc., Tulsa, OK, USA) and the SNPassoc package for $\mathrm{R}$. The association between genotypes and $\mathrm{EH}$ risk was measured by multiple logistic regression analysis to calculate odds ratios (OR) with $95 \%$ confidence intervals (CI) and adjusted for age and gender. Pairwise gene-gene interactions were evaluated by log-likelihood ratio test (LRT) assuming codominant, dominant, and recessive models and adjusted for age and gender (31). Generalized linear model (GLM) was used for the genotype-phenotype correlation analysis to evaluate the differences in the relative mRNA expression levels among carriers with different genotypes using data from 270 HapMap subjects.

\section{Results}

No departure from Hardy-Weinberg equilibrium for investigated SNPs was noted in both $\mathrm{EH}$ and control groups $(P>0.05)$. Allele and genotype frequencies in the studied groups were compatible with those reported in European populations. Table 2 shows genotype and allele frequencies of CYP2C subfamily gene polymorphisms in both case and control groups. Variant allele and genotypes of CYP2C8 rs7909236 were found to be significantly associated with increased risk of essential hypertension $(P \leq$ 0.001 ). As can be seen from Table 2, association between genotypes $C Y P 2 C 8$ and $\mathrm{EH}$ risk remained statistically significant after adjustment for age and sex $(P=0.005)$. Moreover, allele $\mathrm{C}(\mathrm{OR}=$ 
Table 2. Genotype and allele frequencies of CYP2C subfamily gene polymorphisms in hypertensive patients and controls.

\begin{tabular}{|c|c|c|c|c|c|}
\hline Gene, polymorphism & Genotype, allele & $\begin{array}{l}\text { Controls, } \\
n(\%)^{1}\end{array}$ & $\begin{array}{l}\text { EH patients, } \\
n(\%)^{1}\end{array}$ & $\begin{array}{c}P \text {-value } \\
\text { OR }(95 \% \mathrm{Cl})^{2}\end{array}$ & $\begin{array}{c}P \text {-value } \\
\text { adj OR }(95 \% \mathrm{Cl})^{3}\end{array}$ \\
\hline \multirow[t]{5}{*}{ CYP2C8, G > T (rs7909236) } & GG & $262(67.0)$ & $242(56.9)$ & 0.001 & 0.005 \\
\hline & GT & $118(30.2)$ & $151(35.5)$ & $1.27(0.95-1.71)$ & $1.38(0.99-1.93)$ \\
\hline & $\mathrm{TT}$ & $11(2.8)$ & $32(7.5)$ & $2.81(1.40-5.66)$ & $2.99(1.39-6.44)$ \\
\hline & $\mathrm{T}$ & 0.179 & 0.253 & 0.0003 & - \\
\hline & & & & $1.55(1.22-1.97)$ & \\
\hline \multirow{4}{*}{ CYP2C8, T > C (rs1934953) } & $\mathrm{TT}$ & $181(46.3)$ & $178(41.9)$ & 0.084 & 0.083 \\
\hline & $\mathrm{TC}$ & $181(46.3)$ & $197(46.4)$ & $1.11(0.83-1.48)$ & $1.09(0.82-1.46)$ \\
\hline & CC & $29(7.4)$ & $50(11.8)$ & $1.75(1.06-2.90)$ & $1.76(1.06-2.90)$ \\
\hline & $\mathrm{C}$ & 0.306 & 0.349 & $0.061 .22(0.99-1.50)$ & - \\
\hline \multirow[t]{5}{*}{ CYP2C9, C > G (rs9332242) } & $\mathrm{CC}$ & $305(79.6)$ & $337(80.0)$ & 0.558 & 0.568 \\
\hline & CG & $71(18.5)$ & $80(19.0)$ & $1.02(0.71-1.45)$ & $1.03(0.72-1.47)$ \\
\hline & GG & $7(1.8)$ & $4(1.0)$ & $0.52(0.15-1.78)$ & $0.52(0.15-1.81)$ \\
\hline & $\mathrm{G}$ & 0.111 & 0.105 & 0.677 & - \\
\hline & & & & $0.94(0.68-1.28)$ & \\
\hline \multirow[t]{5}{*}{ CYP2C19, G > A (rs4244285) } & GG & $305(78.0)$ & $341(80.2)$ & 0.119 & 0.117 \\
\hline & $\mathrm{GA}$ & $74(18.9)$ & $80(18.8)$ & $0.99(0.70-1.41)$ & $0.95(0.65-1.39)$ \\
\hline & AA & $11(3.1)$ & $4(0.9)$ & $0.35(0.12-1.06)$ & $0.29(0.08-1.05)$ \\
\hline & A & 0.123 & 0.104 & 0.21 & - \\
\hline & & & & $0.82(0.61-1.12)$ & \\
\hline
\end{tabular}

\footnotetext{
1 Absolute number and percentage of individuals with particular genotype.

2 Odds ratio with $95 \%$ confidence intervals (codominant genetic model).

${ }^{3}$ Odds ratio with $95 \%$ confidence intervals adjusted for age and gender with two degrees of freedom.

Bolded is statistically significant $P$ value.
}

$1.2295 \% \mathrm{CI} 0.99-1.50, P=0.06)$ and genotype CC (OR $=1.6695 \%$ CI 1.03-2.69, $P=0.035$, recessive genetic model) of CYP2C8 rs1934953 were also associated with increased hypertension risk, but at a borderline statistical significance. However, odds ratio of $\mathrm{EH}$ risk in the carriers of $\mathrm{CYP} 2 \mathrm{C} 8 \mathrm{CC}$ remained significant after adjustment for age and sex $(\mathrm{OR}=1.6895 \% \mathrm{CI} 1.04-2.72, P=$ 0.031). In addition, SNP rs4244285 of CYP2C19 tended to be associated with a decreased risk of $\mathrm{EH}$ : Adjusted odds ratio for sex and age in the carriers of genotype AA was 0.29 (95\%CI $0.08-$ $1.05, P=0.04$ ).

Then, we applied a log-likelihood ratio in order to assess join effects of CYP2C subfamily gene polymorphisms on EH risk. Table 3 shows data on the analysis for epistatic interactions between CYP2C subfamily gene polymorphisms in essential hypertension, as evaluated by SNPassoc package for $\mathrm{R}$. Although, no statistically significant epistatic interactions between the genes were observed, the crude effect of rs1934953 on the EH risk was noted ( $P=0.033$, recessive genetic model). Further analysis for gene-gene interactions (Table 4) observed that five genotype combinations were associated with increased risk of hypertension. However, the only genotype combination CYP2C8 rs7909236 TT $\times$ CYP2C19 rs4244285 GG was significantly associated with EH risk after adjustment for multiple testing $(P=$ 0.004).

Genotype-phenotype correlation analysis for CYP2C subfamily gene polymorphisms was preformed using the data on both mRNA expression levels and genotypes for these genes obtained from 270 HapMap individuals. The relative expression levels of CYP2C subfamily genes mRNA by different genotypes are shown in Figure 1(A, B, C and D). The levels of CYP2C8 mRNA were significantly correlated with SNP rs2228099 $(P=0.01$, Figure 1A) at dominant genetic model, as evaluated by GLM. No significant genotype-phenotype correlations were found for other investigated SNPs. in silico functional analysis performed by the SNP function prediction tool observed a regulatory potential for SNP rs1934953 of the

Table 3. Epistatic interactions between CYP2C subfamily gene polymorphisms in essential hypertension. (Gene-gene interactions are evaluated by SNPassoc package for R [González JR et al, 2007]).

\begin{tabular}{|c|c|c|c|c|c|}
\hline SNPs & $\begin{array}{l}\text { Genetic } \\
\text { models }\end{array}$ & $\begin{array}{c}\text { CYP2C8 } \\
\text { (rs7909236) } \\
\end{array}$ & $\begin{array}{c}\text { CYP2C8 } \\
\text { (rs1934953) }\end{array}$ & $\begin{array}{c}\text { CYP2C9 } \\
\text { (rs9332242) }\end{array}$ & $\begin{array}{c}\text { CYP2C19 } \\
\text { (rs4244285) }\end{array}$ \\
\hline \multirow[t]{2}{*}{ (rs7909236) } & Dominant & - & - & - & - \\
\hline & Recessive & - & - & - & - \\
\hline \multirow{3}{*}{$\begin{array}{l}\text { CYP2C8 } \\
\quad \text { (rs1934953) }\end{array}$} & Codominant & - & 0.086 & 0.052 & - \\
\hline & Dominant & - & 0.236 & 0.663 & - \\
\hline & Recessive & - & 0.033 & - & - \\
\hline \multirow{2}{*}{ (rs9332242) } & Recessive & - & 0.488 & 0.295 & - \\
\hline & Overdominant & - & 0.917 & 0.835 & - \\
\hline CYP2C19 & Codominant & - & - & - & - \\
\hline \multirow{3}{*}{ (rs4244285) } & Dominant & - & - & - & - \\
\hline & Recessive & - & - & - & - \\
\hline & Overdominant & - & - & - & - \\
\hline
\end{tabular}

The upper part of the matrix contains the $P$ values for epistatic interactions evaluated by log-likelihood ratio (LRT) test. The diagonal contains the $P$ values from LRT for the crude effect of each SNP. The lower triangle contains the $P$ values from LRT comparing the two-SNP additive likelihood to the best of the single-SNP models. Bolded is statistically significant $P$ value for SNP-SNP interactions. $P$ values are adjusted for age and gender. 
Table 4. Overall associations between genotype combinations of CYP2C subfamily gene SNPs and essential hypertension risk.

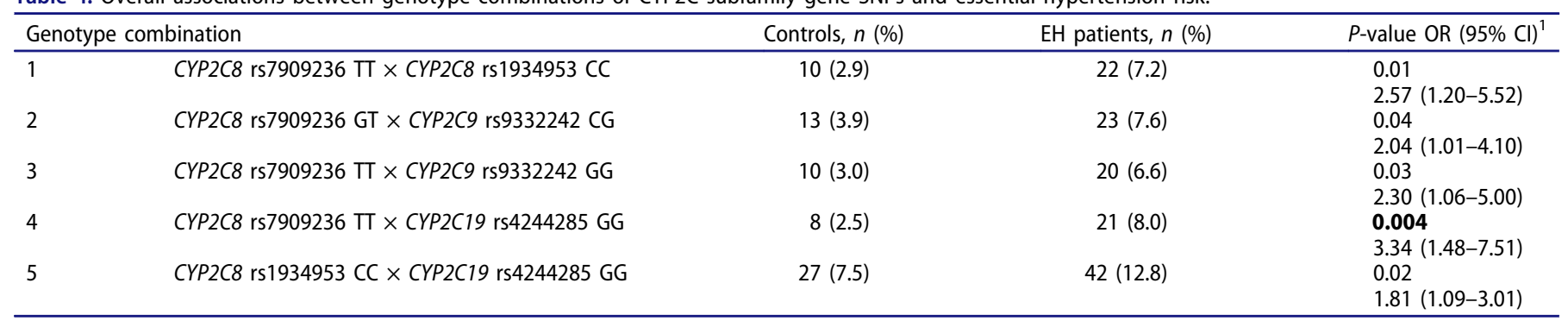

${ }^{1}$ Crude odds ratio with $95 \%$ confidence intervals;

Bolded is statistically significant genotype combination after adjustment for multiple testing.

CYP2C8 gene (Figure 1E it is indicated by right red box). A SNP rs9332242 is located at binding sites for mRNA. Furthermore, SNP rs7909236 is located at binding site for a number of transcription factors suggesting a functional significance of this polymorphism of CYP2C8.

\section{Discussion}

In the present study, we investigated whether common polymorphisms of CYP2C8, CYP2C9, and CYP2C19, genes involved into the epoxygenase pathway arachidonic acids metabolism, are associated with susceptibility to essential hypertension in Russian population. We found that SNPs rs7909236 and rs1934953 of the CYP2C8 gene were significantly associated with increased risk of essential hypertension, whereas SNP rs4244285 of CYP2C19 tended to be associated with decreased risk of the disease. Analysis for gene-gene interactions revealed that combination of genotypes CYP2C8 rs7909236 TT and CYP2C19 rs4244285 GG was significantly associated with increased risk of essential hypertension. Genotype-phenotype correlation analysis showed that the levels of CYP2C8 mRNA were significantly correlated with SNP rs7909236. Functional prediction analysis performed in silico revealed the functionality of majority of investigated SNPs: a regulatory potential observed for SNP rs1934953 of CYP2C8, SNP rs9332242 of CYP2C8 is located at binding sites for mRNA, and SNP rs7909236 of CYP2C8 is located at binding site for multiple of transcription factors.

To our knowledge, the present study was the first to show that the investigated polymorphisms such as rs7909236 and rs1934953 of CYP2C8 and also rs4244285 of CYP2C19 could be novel genetic markers of susceptibility to essential hypertension. We also found for the first time that synergistic interactions between polymorphic genes of CYP2C subfamily, at least between CYP2C8 rs7909236 and CYP2C19 rs4244285 loci, contribute to the increased disease risk. However, the key finding was an increased risk for $\mathrm{EH}$ in carriers of the variant T alleles of rs7909236. CYP2C8 is a cytochrome P450 enzyme possessing epoxygenase activity and catalyzing an NADPHand oxygen-dependent conversion of arachidonic acid to a cis-epoxyeicosatrienoic acid. The enzyme plays a major role in the metabolism of therapeutically important drugs exhibiting large interindividual differences in their pharmacokinetics (32). In fact, little is known about how the expression of the CYP2C8 gene is regulated. It is known that rs7909236 $\left(-271 \mathrm{C}>\mathrm{A}, \mathrm{CYP} 2 \mathrm{C} 8^{\star} 1 B\right)$ is a promoter SNP located at -271 from the translational start of the CYP2C8 gene, and the variant allele has been suggested to result in the creation of a C/EBPalpha transcription factor consensus sequence and associated with increased transcription factor binding and promoter activity $(32,33)$. However, this is contrary to our finding obtained on the HapMap data. We found that the levels of CYP2C8 mRNA were decreased in the carriers of genotype GT suggesting a downregulation effect of this variant on the gene expression. Indeed, polymorphism rs7909236 of $C Y P 2 C 8$ could be the target for a number of transcription factors, as we identified in silico by the function prediction tool. This means that the expression of CYP2C8 is controlled by diverse regulatory mechanisms such as inducible activation by transcription factors, each of which bind to specific regulatory elements in this 5'-upstream region of the gene. We did not find effects of other SNPs investigated in this study on the expression levels of corresponding genes. Moreover, no any functional studies were found in the literature regarding to functional significance for that SNPs. This makes further interpretation of association of these SNPs with hypertension phenotype difficult.

Given that CYP2C-derived EETs are potent vasodilators, persons with diminished capacity to synthesize EETs due to the downregulation of $C Y P 2 C 8$ expression (i.e., carriers of the -271T allele of rs7909236) might be more susceptible to essential hypertension. Based on the reviewed literature ( 9 , $10,11,14)$, we proposed the mechanisms by which plausible deficiency of CYP2C-derived EETs in carriers of the -271T allele of $C Y P 2 C 8$ might cause hypertension include: a) decreased vasorelaxation and increased peripheral vascular resistance due to diminished ion channel-dependent activation and insufficiency to stimulate the formation and release of natural vasodilators (action as an endothelial derived hyperpolarizing factor), b) increased cardiac contractility and heart rate, c) increased cortical renin release and decreased sodium excretion in kidneys due activating epithelial sodium channel, and d) promoted both apoptotic and oxidative vascular injury. Certainly, it is crucial that, before drawing definitive conclusions about the mechanisms proposed above, experimental and clinical studies utilizing cutting edge molecular and biochemical technologies are required to substantiate genotype-phenotype relationships in the epoxygenase pathway of AA metabolism underlying hypertension pathogenesis.

The present study has some limitations. A majority of the associations of SNPs with hypertension risk were not strong, 
A

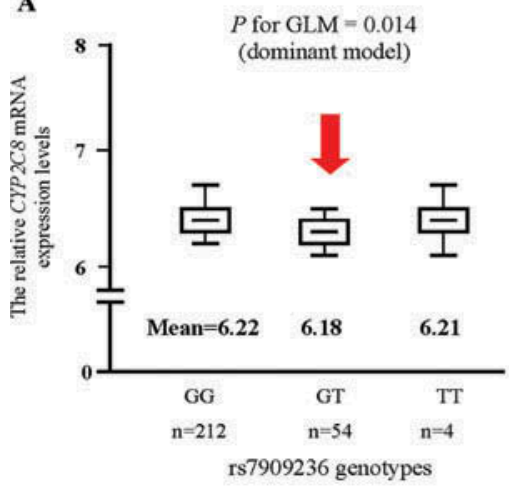

C

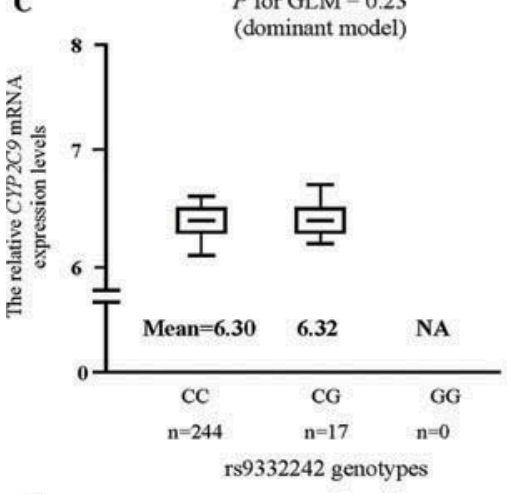

B
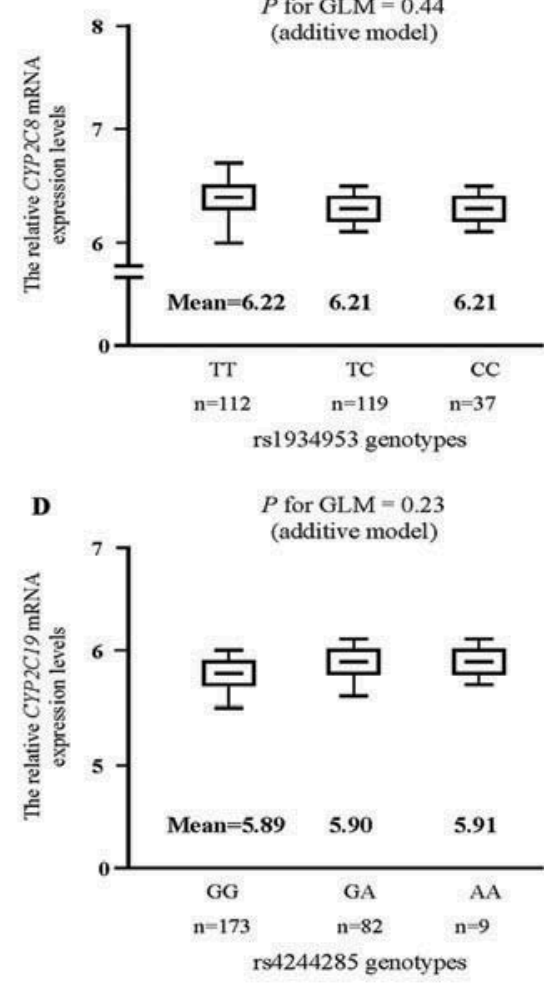

$\mathbf{E}$

\begin{tabular}{|c|c|c|c|c|c|c|c|c|c|c|c|c|c|c|c|c|}
\hline ż & $\underset{\mathrm{s}}{\text { 具 }}$ & 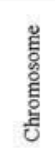 & 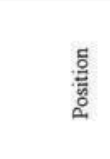 & 幽 & 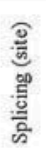 & 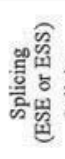 & 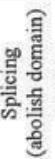 & 歪 & 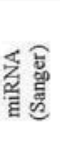 & 峁 & $\begin{array}{l}\text { कृ } \\
\text { ठ } \\
\text { के } \\
\text { ळे }\end{array}$ & 竎 & 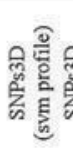 & 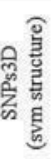 & 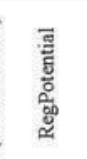 & 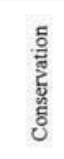 \\
\hline 1 & rs1934953 & 10 & 96787460 & -. & .. & -. & -- & - & -. & - & .. & -. & - & -. & 0.21886 & 0.000 \\
\hline 2 & rs 4244285 & 10 & 96531606 & .. & .. & -. & .. & - & .. & - & .. & -. & -. & .. & 0.0 & 0.642 \\
\hline 3 & rs 7909236 & 10 & 96819420 & $\mathrm{Y}$ & - & - & -. & - & .. & - & .. & -. & - & - & 0.0 & 0.000 \\
\hline 4 & rs 9332242 & 10 & 96738883 & .. & .. & -. & .. & $\mathrm{Y}$ & $\mathrm{Y}$ & - & .. & .. & - & - & 0.0 & 0.002 \\
\hline
\end{tabular}

Figure 1. Functional analysis of CYP2C subfamily gene polymorphisms. A, B, C, and D. The relative expression levels of CYP2C subfamily genes mRNA by different genotypes in 270 HapMap subjects from four populations analyzed by the HumanWG-6 Expression BeadChip and evaluated by SNPexp v1.2 online tool (Norwegian PSC Research Center, http://app3.titan.uio.no/biotools/tool.php?app=snpexp). Red arrow shows significant effects of SNP on gene expression levels. The effects of SNPs on mRNA levels of corresponding genes are evaluated by generalized linear models (GLM). E. SNP function prediction results evaluated by FuncPred online tool (National Institute of Environmental Health Sciences, https://snpinfo.niehs.nih.gov/snpinfo/snpfunc.htm). NA, not available; TFBS, Transcription Factor Binding Sites; ESE, Exonic Splicing Enhancer; ESS, Exonic Splicing Silencer; Polyphen, predicted damaging nsSNPs; RegPotential, Regulatory Potential Score; Y, Yes; N, No.

thereby showing small-to-modest effects of these genes on disease phenotype. Because a limited number of SNPs were selected for this study, our findings do not allow any definitive conclusion yet to be made on the comprehensive contribution of the genes to hypertension susceptibility. This means that the results of our study require further investigation in other population-based studies to address issues discussed above, but these studies will need to be substantially larger than the present investigation. It is important to note that since essential hypertension is a multifactorial disease determined by a complex interplay between genetic and environmental factors, further genetic studies should take into account disease-associated environmental risk factors to better understand the molecular mechanism of the disease development.

Nevertheless, a preliminary conclusion has to be made that polymorphic genes of CYP2C subfamily are important determinants of genetic susceptibility to essential hypertension. An association between polymorphisms of these genes and hypertension demonstrates the importance of the epoxygenase pathway in the metabolism of arachidonic acids for the disease pathogenesis. Understanding the relationships between altered $C Y P 2 C 9$ gene expression and hypertension pathophysiology should suggest specific targeted interventions that will expand the therapeutic options for hypertensive individuals in future. For instance, the modulation of EET pathway through stimulation of residual enzyme activity represents a promising pharmacological target that may improve the clinical management of hypertensive patients and healthy individuals at high cardiovascular risk.

\section{Declaration of interest}

The authors report no conflicts of interest. The authors alone are responsible for the content and writing of the paper. 


\section{References}

1. Chobanian AV, Bakris GL, Black HR, et al. The seventh report of the joint national committee on prevention, detection, evaluation, and treatment of high blood pressure: the JNC 7 report. JAMA 2003;289:2560-2572.

2. Joffres M, Falaschetti E, Gillespie C, et al. Hypertension prevalence, awareness, treatment and control in national surveys from England, the USA and Canada, and correlation with stroke and ischaemic heart disease mortality: a cross-sectional study. BMJ Open 2013;3(8):e003423.

3. Ehret GB, Munroe PB, Rice KM, et al. Genetic variants in novel pathways influence blood pressure and cardiovascular disease risk. Nature 2011;478:103-109.

4. Basson J, Simino J, Rao DC. Between candidate genes and whole genomes: time for alternative approaches in blood pressure genetics. Curr Hypertens Rep 2012;14:46-61.

5. Ehret GB, Caulfield MJ. Genes for blood pressure: an opportunity to understand hypertension. Eur Heart J 2013;34:951-961.

6. Padmanabhan S, Caulfield M, Dominiczak AF. Genetic and molecular aspects of hypertension. Circ Res 2015;116:937-959.

7. Singh M, Singh AK, Pandey P, et al. Molecular genetics of essential hypertension. Clin Exp Hypertens 2016;38:268-277.

8. Theken KN, Schuck RN, Edin ML, et al. Evaluation of cytochrome P450-derived eicosanoids in humans with stable atherosclerotic cardiovascular disease. Atherosclerosis 2012;222:530-536.

9. Bellien J, Joannides R. Epoxyeicosatrienoic acid pathway in human health and diseases. J Cardiovasc Pharmacol 2013;61:188-196.

10. Imig JD. Epoxyeicosatrienoic acids, hypertension, and kidney injury. Hypertension 2015;65:476-482.

11. Capdevila J, Wang W. Role of cytochrome P450 exoxygenase in regulating renal membrane transport and hypertension. Curr Opin Nephrol Hypertens 2013;22:163-169.

12. Spector AA, Kim HY. Cytochrome P450 epoxygenase pathway of polyunsaturated fatty acid metabolism. Biochim Biophys Acta 2015;1851:356-365.

13. Theken KN, Lee CR. Genetic variation in the cytochrome P450 epoxygenase pathway and cardiovascular disease risk. Pharmacogenomics 2007;8:1369-1383.

14. Zordoky BN, El-Kadi AO. Effect of cytochrome P450 polymorphism on arachidonic acid metabolism and their impact on cardiovascular diseases Pharmacol Ther 2010;125:446-463.

15. McGiff JC. Cytochrome P450 metabolism of arachidonic acid. Annu Rev Pharmacol Toxicol 1991;31:339-369.

16. Wu S, Moomaw CR, Tomer KB, et al. Molecular cloning and expression of CYP2J2, a human cytochrome $\mathrm{P} 450$ arachidonic acid epoxygenase highly expressed in heart. J Biol Chem 1996;271:3460-3468.

17. Lee CR, Imig JD, Edin ML, et al. Endothelial expression of human cytochrome P450 epoxygenases lowers blood pressure and attenuates hypertension-induced renal injury in mice. FASEB J. 2010;24:3770-3781.
18. King LM, Gainer JV, David GL, et al. Single nucleotide polymorphisms in the CYP2J2 and CYP2C8 genes and the risk of hypertension. Pharmacogenet Genomics 2005;15:7-13.

19. Dreisbach AW, Japa S, Sigel A, et al. The Prevalence of CYP2C8, 2C9, 2J2, and soluble epoxide hydrolase polymorphisms in African Americans with hypertension. Am J Hypertens 2005;18:1276-1281.

20. Wu SN, Zhang Y, Gardner CO, et al. Evidence for association of polymorphisms in CYP2J2 and susceptibility to essential hypertension. Ann Hum Genet 2007;71:519-525.

21. Ma Y, Ni W, Zhu W, et al. Association of genetic polymorphisms of CYP 2C19 with hypertension in a Chinese Han population. Blood Press 2011;20:166-170.

22. Zhu Q, Amjad A, Fu Z, et al. Single nucleotide polymorphism of the CYP2J2 gene is associated with essential hypertension in Uygur population in China. Biochem Anal Biochem 4:159.

23. Shin DJ, Kwon J, Park AR, et al. Association of CYP2C19*2 and *3 genetic variants with essential hypertension in Koreans. Yonsei Med J 2012;53:1113-1119.

24. Alghasham A, Ali A, Ismail H, et al. CYP2J2 -50 G/T and ADRB2 G46A gene polymorphisms in Saudi subjects with hypertension. Genet Test Mol Biomarkers 2012;16:1027-1031.

25. Ali AAA, Wassim NM, Dowaidar M, Yaseen AE. Association of eNOS (E298D) and CYP2J2 (- 50G/T) gene polymorphisms with hypertension among Egyptian cases. The Journal of Basic and Applied Zoology 2013;66:234-241.

26. Polonikov AV, Ivanov VP, Solodilova MA, et al. A common polymorphism G-50T in cytochrome P450 2J2 gene is associated with increased risk of essential hypertension in a Russian population. Dis Markers 2008;24:119-126.

27. Tzveova R, Naydenova G, Yaneva T, et al. Gender-specific effect of CYP2C $8{ }^{\star} 3$ on the risk of essential hypertension in Bulgarian patients. Biochem Genet 2015;53:319-333.

28. Bushueva O, Solodilova M, Churnosov M, et al. The flavincontaining monooxygenase 3 gene and essential hypertension: the joint effect of polymorphism E158K and cigarette smoking on disease susceptibility. Int J Hypertens 2014;2014:712169.

29. Polonikov AV, Ushachev DV, Ivanov VP, et al. Altered erythrocyte membrane protein composition mirrors pleiotropic effects of hypertension susceptibility genes and disease pathogenesis. J Hypertens. 2015;33:2265-2277.

30. Xu Z, Taylor JA. SNPinfo: integrating GWAS and candidate gene information into functional SNP selection for genetic association studies. Nucleic Acids Res 2009;37(Web Server issue):W600-W605.

31. González JR, Armengol L, Solé X, et al. SNPassoc: an R package to perform whole genome association studies. Bioinformatics 2007;23:644-645.

32. Rodríguez-Antona C, Niemi M, Backman JT, et al. Characterization of novel CYP2C8 haplotypes and their contribution to paclitaxel and repaglinide metabolism. Pharmacogenomics J 2008;8:268-277.

33. Kirchheiner J, Meineke I, Fuhr U, et al. Impact of genetic polymorphisms in CYP2C8 and rosiglitazone intake on the urinary excretion of dihydroxyeicosatrienoic acids. Pharmacogenomics 2008;9:277-288. 